\title{
A PRÁTICA DOCENTE EM EDUCAÇÃO A DISTÂNCIA: O USO DO MODELO METODOLÓGICO DOS TRÊS MOMENTOS PEDAGÓGICOS
}

Amanda Bifano Balbinot ${ }^{1}$, Ana Marli Bulegon ${ }^{1}$, Elaine Harada Teixeira de Oliveira ${ }^{2}$, Patricia Alejandra Behar ${ }^{1}$, Vera Catarina Castiglia Portella ${ }^{1}$

\author{
${ }^{I}$ Programa de Pós-Graduação em Informática na Educação - Universidade Federal do Rio Grande \\ do Sul (UFRGS) \\ ${ }^{2}$ Departamento de Ciência da Computação - Universidade Federal do Amazonas (UFAM)
}

\{ambalbinot@gmail.com,anabulegon@gmail.com,veraportella@gmail.com,elaine@dcc.ufam.edu.br, pbehar@terra.com.br\}

\section{RESUMO}

Este artigo apresenta a metodologia utilizada num trabalho desenvolvido em uma disciplina de um curso de pós-graduação. $O$ trabalho consiste na implementação de um Objeto de Aprendizagem (OA), cujo tema decorre da discussão entre o papel do professor virtual e do professor presencial. O OA, tinha como objetivo apresentar uma reflexão sobre o papel do professor nessa mudança de paradigma e estava estruturado segundo o modelo metodológico dos Três Momentos Pedagógicos (TMP). Esse modelo metodológico permitiu verificar o conhecimento prévio dos alunos sobre o tema, desenvolver as discussões da oficina através dessa verificação e aplicá-lo através de reflexão. Verificou-se que houve amadurecimento das concepções que se tinha antes e ao final da oficina.

Palavras-Chave: prática virtual docente, ensino e aprendizagem a distância, Três Momentos Pedagógicos.

Abstract: This paper presents the methodology used in a work done in a graduate course. The work involves the implementation of a Learning Object (LO), whose theme arises from the discussion between the roles of a virtual teacher and a traditional one. The LO was intended to provide a reflection on teacher's role in this paradigm shift. The LO structure was based on the methodological model of the Three Pedagogical Moments, which allowed us to verify students' prior knowledge on the subject, develop the workshop discussions by this verification and apply it through reflection. It was possible to verify that the concepts the students had were more mature at the end of the workshop than before.

Keywords: virtual teaching practice, distance education and learning, Three Pedagogical Moments. 


\section{Introdução}

Na década de 90, mais especificamente, com a utilização da Internet, ocorreram mudanças significativas nas formas de aquisição da informação e, como consequiência, no processo de aprendizagem. A educação à distância já ocorria há muito tempo, com o uso de cursos por correspondência, mas com as novas tecnologias de informação e comunicação (TIC), iniciaram-se os cursos de Educação a Distância (EAD), com uso de ambientes virtuais de aprendizagem (AVA). Assim, conforme Behar et al. (2009, p.17) a utilização de tecnologia na educação, nas instituições brasileiras torna-se imprescindível para formação/capacitação, o que requer "o estudo de propostas teóricometodológicas e uma ampla divulgação de experiências em EAD, bem como uma reflexão das mesmas".

O papel do professor vem passando por transformações, pois o ensino mediado por novas tecnologias vem retirando alunos e docentes das salas de aula, devido à possibilidade de atividades virtuais, ou seja, à distância. Desta forma, para a prática docente torna-se relevante abordar aspectos sobre a atividade docente em ambientes virtuais, analisar as transformações do ensino presencial para o virtual, tanto o papel do professor como do aluno e as estratégias didáticas. Essas mudanças requerem novas habilidades do docente e uma nova postura tanto deles quanto dos alunos. $\mathrm{O}$ uso das TIC na educação tem sido um assunto muito discutido entre os educadores e comunidade educacional de um modo geral. Diante dessa discussão, o papel do professor virtual bem como da metodologia de trabalho que ele usa para desenvolver seu trabalho pedagógico, são uma preocupação constante. Portanto, as reflexões e possibilidades sobre a adoção das tecnologias na educação, são importantes na busca incessante de soluções e de melhoria da qualidade do ensino. A utilização de recursos tecnológicos poderá, ou não, ocasionar transformações na aprendizagem (Zavaski, 2005).

O ambiente virtual separa professor e aluno fisicamente, gerando, dessa forma, mudanças significativas na ação docente. O professor assume o papel de orientador; apresenta modelos, faz mediações, explica, redireciona o foco e oferece opções. $\mathrm{Na}$ comunicação por meio virtual, acompanha-se o processo de aprendizagem, esclarecendo dúvidas, identificando dificuldades e sugerindo atividades; em discussões, o professor pode dar mais liberdade para os alunos, e também, manter uma forte presença na conversação para corrigir, informar, opinar, solicitar a participação dos alunos (Sherry, 1998). Pela distância física, as colocações feitas aos alunos assumem um papel de destaque, ocorrendo a necessidade de feedback constantemente, para reforçar a participação e orientar os alunos, que podem sentir-se sem assistência, sozinhos ao não obterem retorno de sua participação ou de suas dúvidas.

Para Collins e Berge (1996), o professor se torna um questionador eficiente em vez de um provedor de respostas. A atividade a distância pode e deve propiciar trabalhos colaborativos, que permitam a análise dos problemas propostos sob diferentes prismas. Os trabalhos propostos em grupo podem produzir significados e soluções através de uma compreensão compartilhada entre os alunos e mediada pelo docente.

Percebe-se que aspectos e conceitos sobre a educação a distancia encontram-se, de certa forma, difundidos. No entanto, a inquietação está na distância entre o discurso e 
a prática sobre a utilização de metodologias de trabalho dos cursos virtuais, ou seja, fala-se em mudar o estilo de trabalho nas aulas de EAD, mas muitas vezes, continua-se a usar o mesmo estilo de trabalho, onde o professor transmite seu conhecimento e o aluno permanece como receptor da informação.

Surgem dentro deste contexto de mudanças questionamentos como: existem diferenças entre o ensino presencial e o virtual? Como deve ser a comunicação entre professor e aluno no ambiente virtual? O professor que tem experiência com docência presencial estará preparado para o ensino no ambiente computacional? Frente a estas questões, surgiu o interesse de se analisar quem é o professor virtual e qual o seu papel no processo de ensino e de aprendizagem atual. Além disso, desejou-se verificar a possibilidade de uso do modelo metodológico dos Três Momentos Pedagógicos (TMP) para uma maior eficiência na aprendizagem em aulas virtuais. Acredita-se que este trabalho servirá como subsídio para novas reflexões sobre a temática para todos que se interessam ou trabalham com EAD.

A partir dessas considerações, que caracterizam mudança de paradigma da prática docente, elaborou-se um OA em forma de oficina sobre o papel do professor virtual, com o intuito de oferecer subsídios para educadores em geral e propor elementos que possam desencadear estudos mais profundos sobre a temática. Esse artigo apresenta um relato de experiência da aplicação de um Objeto de Aprendizagem (OA) em uma disciplina de um curso de pós-graduação cujo tema é a discussão entre o papel do professor virtual e do professor presencial (habilidades, competências, saberes, etc.). Esse OA está estruturado segundo o modelo metodológico dosTrês Momentos Pedagógicos (TMP) de Delizoicov e Angotti (1991). Esse modelo metodológico parte de uma temática central que perpassa por todas as unidades subseqüentes. Ele tem como objetivo contemplar as dimensões dialógica e problematizadora do processo educativo proposto por Paulo Freire (Delizoicov e Angotti, 1991).

O modelo metodológico adotado é apresentado na próxima seção. A seção 3 apresenta a metodologia de trabalho da oficina realizada. Na seção 4, são feitas algumas discussões sobre os resultados obtidos. $\mathrm{Na}$ última seção, são feitas as considerações finais.

\section{Modelo metodológico dos Três Momentos Pedagógicos (TMP)}

Uma prática muito comum no processo de ensino e de aprendizagem é o professor preparar suas aulas com certa antecedência e ministrá-las aos alunos, seguindo estrita e rigidamente o seu planejamento. $\mathrm{O}$ mesmo conteúdo e planejamento se aplicam às suas diferentes turmas, de diferentes cursos e de diferentes épocas. Muitas vezes, a lista de exercícios utilizada é a mesma anos a fio. Todos os alunos que estão para cursar a disciplina já conhecem o estilo do professor por seus colegas veteranos. E podem encontrar maneiras de terem boas notas, mas sem um aproveitamento efetivo. Uma das possibilidades de mudar essa situação é utilizar o modelo metodológico dos Três Momentos Pedagógicos (TMP), onde o professor pode ter uma noção do conhecimento prévio dos alunos para organizar a melhor forma de trabalhar e, assim, aplicar o conhecimento de maneira eficaz. 
Delizoicov et al. (2002), que trabalharam com o modelo TMP, desenvolveram uma proposta de "trabalho didático-pedagógico que permite tanto a apreensão dos conceitos, leis, relações da Física e sua utilização, bem como a sua aproximação com fenômenos ligados a situações vividas pelos alunos, sejam as de origem natural, sejam as de origem tecnológica." Essa proposta propõe um modelo metodológico estruturado em três fases/etapas: Problematização Inicial (PI), Organização do Conhecimento (OC) e Aplicação do Conhecimento (AC).

Segundo esse modelo, durante a PI, são apresentadas, aos alunos, questões ou situações que estejam relacionadas com o assunto a ser abordado e que, ao mesmo tempo, tenham um potencial problematizador. Esse momento visa levantar as concepções prévias dos alunos a respeito do assunto a ser tratado em aula. Neste momento, a função do professor é mais de questionar e lançar dúvidas sobre o tema estudado do que fornecer explicações (Delizoicov et al., 2002).

$\mathrm{Na}$ etapa da $\mathrm{OC}$, os conhecimentos necessários à compreensão do assunto abordado e ao encaminhamento de soluções para as questões da PI devem ser sistematicamente estudados sob o estímulo do professor. É a etapa do desenvolvimento de conhecimentos novos para o aluno. Nesse momento pedagógico, cabem as mais diver sas estratégias de ensino como: exposição pelo professor, debates, mesas redondas, seminários, leitura de textos, analogias, etc. com o uso de diversas ferramentas como: fórum, chat, etc., no sentido de oportunizar aos alunos a vivência de uma variedade de situações e de formas de desenvolvimento cognitivo que permitam atingir a compreensão desejada dos assuntos estudados.

O terceiro momento pedagógico, AC, destina-se à utilização dos conhecimentos construídos pelos alunos para interpretar as situações problematizadas inicialmente, procurando delimitar o grau de compreensão conseguido para as mesmas. É a etapa da verificação da aprendizagem. Ao mesmo tempo, essa etapa deve ser um espaço de exploração de novas situações, preferencialmente vinculadas à vivência cotidiana dos alunos, e que possam ser compreendidas e explicadas utilizando-se o conjunto de conhecimentos, desenvolvidos nas aulas.

Apesar da proposta dos TMP ter sido divulgada com o uso de temas para o ensino de Física, neste trabalho, este modelo metodológico foi utilizado fazendo-se uso da temática: professor presencial e professor virtual.

A seção seguinte apresenta a metodologia de trabalho da oficina e como esse modelo foi aplicado.

\section{Metodologia do trabalho}

Com o objetivo de oportunizar discussões, conhecimento e análise da atividade docente e de estratégias educacionais em ambientes presenciais e virtuais, pretendeu-se levar aos alunos da disciplina "Oficinas Virtuais" uma oficina que discutisse o trabalho docente em atividades presenciais, comparando com atividades virtuais através da abordagem de questões como: quem é o professor virtual?, qual é o papel do professor que ensina em ambiente virtual?, o professor habituado com o ensino presencial está em condições de desenvolver aulas no meio online? 
A oficina foi desenvolvida por meio de encontros presenciais (03) e a distância (01), perfazendo um total de 15 horas de aula. Em cada encontro, foram propiciadas condições para a construção de conhecimento sobre o papel do professor em ambientes presenciais e de educação à distância. As atividades previstas fazem uso das ferramentas do ambiente virtual, tais como: fórum de debates, diário de bordo, sala de bate-papo, email, biblioteca, etc.

O trabalho foi desenvolvido no $1^{\circ}$ semestre do ano de 2009 , dentro de um enfoque qualitativo, tendo como sujeitos de pesquisa uma turma de pós-graduação na área de informática na educação composta por 25 alunos. Os instrumentos para a coleta dos dados foram constituídos de: questionários, observações diretas das aulas, realizadas pelas professoras, participação dos alunos no fórum e no chat.

Para favorecer o processo de ensino e de aprendizagem, foi desenvolvido um objeto de aprendizagem (OA), especificamente para a oficina, conforme a Figura 1.
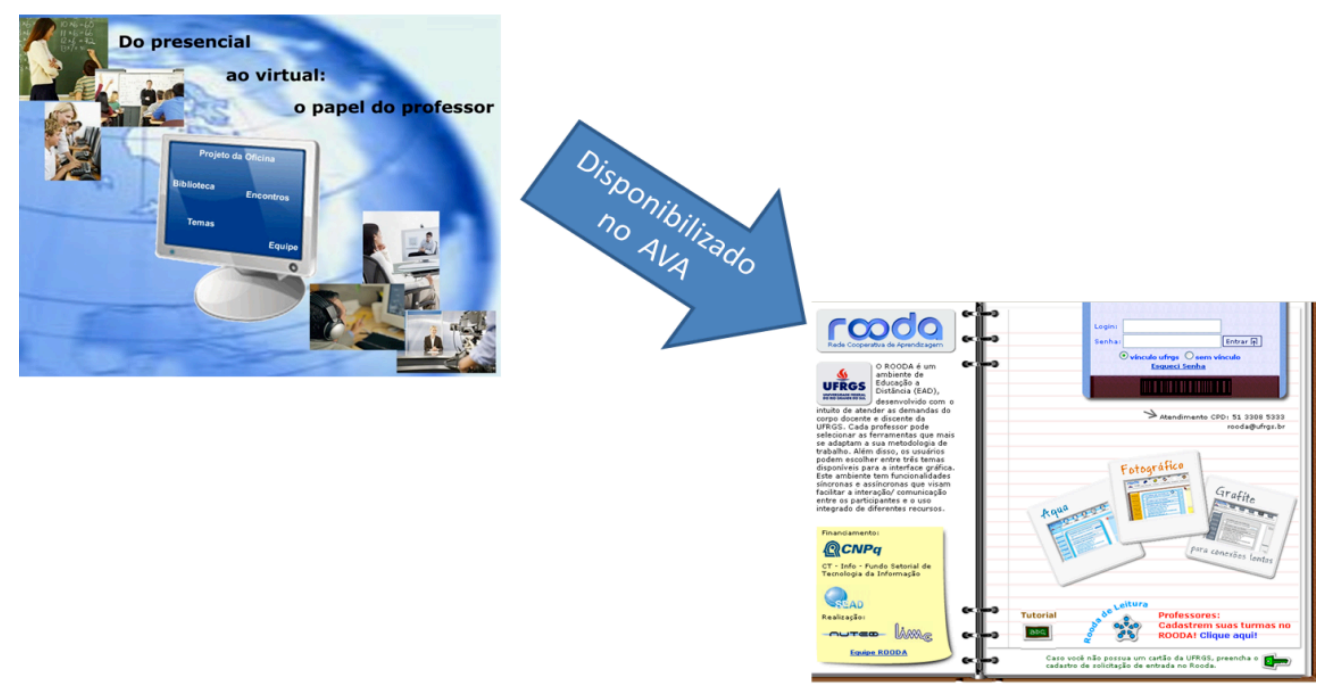

Figura 1: Objeto de aprendizagem desenvolvido e AVA

O OA foi disponibilizado para a turma no ambiente virtual de aprendizagem ROODA, sendo o objeto composto pelos módulos: o Projeto da oficina (apresentação, objetivos, metodologia e avaliação); Encontros (as atividades propostas em cada encontro como, por exemplo, apresentada na Figura 2); Temas (papel do professor virtual, metodologia de trabalho, estratégias didáticas e ambientes virtuais de aprendizagem); Biblioteca (material utilizado na oficina como textos, sites e vídeos e sugestões) e Equipe. 


\section{Encontros e Atividades}

\section{$3^{\circ}$ Encontro}

Encontro virtual

Bate-papo

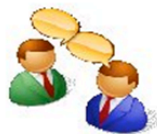

Sobre os seguintes temas:

Experiências como professor e/ou o aluno virtual. Aspectos bons e ruins.

Mídias utilizadas na EAD e possibilidades de uso.

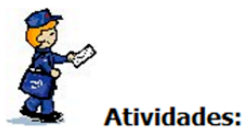

Participação do fórum de discussão com contribuições acerca dos temas discutidos no Bate-papo; Elaboração do trabalho final, plano de aula para EAD, o qual, deverá ser apresentado em aula; Os planos de aula deverão ser postados no webfólio dos grupos antes da apresentação final; Registrar suas impressões no Diário de Bordo.

Figura 2: Objeto de aprendizagem: $3^{\circ}$ Encontro

As atividades propostas no OA em cada encontro estavam estruturadas de acordo com o modelo metodológico dos TMP, conforme pode ser visto no Quadro 1.

Quadro 1. Atividades realizadas de acordo com os TMP

\begin{tabular}{|c|c|c|}
\hline Encontro & $\begin{array}{c}\text { Momento } \\
\text { Pedagógico } \\
\end{array}$ & Atividade \\
\hline \multirow{4}{*}{1} & \multirow{2}{*}{ PI } & Apresentação da oficina \\
\hline & & Verificação de concepções prévias a respeito da temática \\
\hline & \multirow[t]{2}{*}{$\mathrm{OC}$} & $\begin{array}{l}\text { Discussão e reflexão a respeito do papel do professor } \\
\text { presencial e virtual }\end{array}$ \\
\hline & & Apresentação de vídeo \\
\hline 2 & $\mathrm{OC}$ & Apresentação de recursos e estratégias didáticas \\
\hline 3 & $\mathrm{OC}$ & Bate-papo sobre a gestão docente em ambientes virtuais \\
\hline \multirow{3}{*}{4} & \multirow{3}{*}{$\mathrm{AC}$} & $\begin{array}{l}\text { Apresentações dos planos de uma aula para EAD elaborados } \\
\text { em grupo }\end{array}$ \\
\hline & & Reflexões, contribuições e avaliação dos planos de aula \\
\hline & & Verificação das concepções atuais a respeito da temática \\
\hline
\end{tabular}

V. $8 \mathrm{~N}^{\mathrm{o}} 3$, dezembro, 2010 
No $1^{\circ}$ encontro, após as apresentações, foram distribuídos questionários aos alunos cujas questões, a serem respondidas, buscavam verificar suas concepções prévias a respeito da temática: professor presencial e professor virtual, atendendo a proposta do primeiro momento pedagógico - a Problematização Inicial. Para contemplar o segundo momento pedagógico - a Organização do Conhecimento - a partir do que foi respondido nos questionários, propôs-se uma discussão e reflexão a respeito do papel do professor presencial e do virtual. Para isso, usou-se como recurso didático a apresentação de um vídeo sobre a ação docente e as mudanças na forma de ensinar. Após essas discussões o tema do OA foi apresentado aos alunos. Em meio à apresentação abriu-se espaço a questionamentos e a participação dos alunos com suas experiências e percepções sobre a atividade docente virtual, contemplando, dessa forma, a relação dialógica entre professor e aluno. As atividades propostas, bem como, os textos abordados, foram disponibilizados no OA da oficina (Figura 1), no ROODA.

No $2^{\circ}$ encontro, a partir da análise realizada nas respostas dos questionários implementados na PI, abordou-se o assunto professor virtual - recursos e estratégias didáticas. Neste momento foram apresentados alguns Ambientes Virtuais de Aprendizagem (AVA): MOODLE, TELEDUC, ROODA, SAKAI, bem como, recursos em AVA: agenda, correio, bate-papo, diário, exercícios, fóruns, grupos e material de apoio. Esse encontro é parte do segundo momento pedagógico - Organização do Conhecimento.

$\mathrm{O} 3^{\circ}$ encontro, ainda no segundo momento metodológico (OC), ocorreu à distância, pelo chat com o tema 'a gestão docente em ambientes virtuais', o chat foi dividido em dois grupos para facilitar a participação e o acompanhamento das contribuições. Os resultados foram positivos, pela participação de quase $96 \%$ da turma, com colocações muitas vezes fundamentadas em referências bibliográficas, que demonstrou a preparação prévia para a participação no chat. Ocorreram no decorrer da atividade, alguns problemas técnicos, como dificuldade na atualização das mensagens, queda de conexão, mas que foram sendo solucionadas com o auxilio da turma, propondo soluções àqueles que estavam com dificuldades.

O $4^{\circ}$ e último encontro fez parte do terceiro momento pedagógico - a Aplicação do Conhecimento. Destinou-se à verificação da aprendizagem e constituiu-se de apresentações dos planos de uma aula para EAD, construídos em grupos. Após as apresentações, havia um momento para reflexões, contribuições e avaliação. Ao final, aplicou-se outro questionário para verificação das concepções atuais sobre o tema.

Em todos os momentos do processo de ensino nesta oficina, procurou-se verificar, no material escrito e na argumentação oral dos alunos, a presença de indicativos do desenvolvimento de significados claros, diferenciados e transferíveis que pudessem demonstrar a ocorrência da aprendizagem significativa dos conceitos estudados.

\section{Discussão dos resultados}

Os questionários aplicados aos alunos eram compostos de duas questões a serem respondidas no início das atividades, ou seja, na Problematização Inicial (PI) e ao final da oficina, no momento da Aplicação do Conhecimento (AC). As questões buscavam 
verificar as concepções prévias e a posterior evolução da aprendizagem dos alunos a respeito da temática da oficina. Além disso, essas questões versavam sobre o tema da oficina e procuravam contextualizar o assunto escolhido para o estudo. As respostas obtidas foram analisadas e agrupadas de acordo com a semelhança, de forma a expressar a ideia geral. Com base nas respostas traçou-se um paralelo entre as questões e o momento em que foram respondidas, apresentados nos Quadros 2 e 3.

\section{Quadro 2. Problematização Inicial X Aplicação do Conhecimento - Questão 1}

\begin{tabular}{|c|c|}
\hline Problematização Inicial & Aplicação do Conhecimento \\
\hline $\begin{array}{l}\text { Questão 1: Quem é o professor } \\
\text { virtual? }\end{array}$ & $\begin{array}{l}\text { Questão 1: Qual o papel do professor que ensina em } \\
\text { ambiente virtual? }\end{array}$ \\
\hline $\begin{array}{l}\text { Professor EAD ou semi- } \\
\text { presencial }\end{array}$ & Intermediar o processo de ensino e aprendizagem \\
\hline $\begin{array}{l}\text { Utiliza AVAs - recursos } \\
\text { tecnológicos }\end{array}$ & Manter o aluno motivado \\
\hline $\begin{array}{l}\text { Instiga os alunos à pesquisa e a } \\
\text { construção de novos } \\
\text { conhecimentos }\end{array}$ & $\begin{array}{l}\text { Incentivador de uma aprendizagem ativa e } \\
\text { colaborativa }\end{array}$ \\
\hline Orientador & Papel de organizar, orientar \\
\hline Problematizador & Problematizador - de desafiar \\
\hline Mediador & Mediador \\
\hline \multirow[t]{5}{*}{ Precisa de formação específica } & $\begin{array}{l}\text { Proporcionar autonomia, autoria e protagonismo do } \\
\text { aluno }\end{array}$ \\
\hline & Construir o conhecimento com o aluno \\
\hline & $\begin{array}{l}\text { Disponibilizar ferramentas para a reflexão e } \\
\text { construção do conhecimento }\end{array}$ \\
\hline & Facilitador \\
\hline & $\begin{array}{l}\text { Promover a construção do conhecimento de forma } \\
\text { coletiva }\end{array}$ \\
\hline
\end{tabular}

A análise dessas respostas nos permite salientar que a concepção prévia dos alunos sobre o papel do professor virtual não está atrelada apenas aos profissionais que trabalham com a EAD, mas que fazem uso de algum recurso tecnológico e que para isso necessitam de formação específica. Também, nos mostra que o professor não é mais o único detentor do saber, mas um facilitador e orientador da aprendizagem. O professor virtual é aquele que promove a autonomia por meio da construção coletiva do conhecimento e com o uso de ferramentas diversas. 


\section{Quadro 3. Problematização Inicial X Aplicação do Conhecimento - Questão 2}

\begin{tabular}{|c|c|}
\hline Problematização Inicial & Aplicação do Conhecimento \\
\hline $\begin{array}{l}\text { Questão 2: Que diferenças e/ou } \\
\text { semelhanças você vê na metodologia } \\
\text { de trabalho do professor presencial e do } \\
\text { professor virtual? }\end{array}$ & $\begin{array}{l}\text { Questão 2: O professor habituado com o } \\
\text { ensino presencial está em condições de } \\
\text { desenvolver aulas no meio on-line? }\end{array}$ \\
\hline $\begin{array}{l}\text { Diferença: interação à distância entre } \\
\text { professor e aluno }\end{array}$ & Não: precisa de formação em contexto digital \\
\hline $\begin{array}{l}\text { Diferença: utilização de recursos, } \\
\text { métodos e técnicas - maior número de } \\
\text { recursos tecnológicos }\end{array}$ & Não: deve ocorrer a mudança de paradigmas \\
\hline $\begin{array}{l}\text { Diferença: maior dedicação do } \\
\text { professor }\end{array}$ & Sim: precisa capacitação continuada \\
\hline $\begin{array}{l}\text { Diferença: professor deve ter maior } \\
\text { habilidade de escrita. }\end{array}$ & $\begin{array}{l}\text { Sim: deve saber associar os conteúdos com } \\
\text { os novos métodos }\end{array}$ \\
\hline $\begin{array}{l}\text { Diferença: maior flexibilidade em datas } \\
\text { e horários }\end{array}$ & Sim: assumir uma postura de colaboração. \\
\hline $\begin{array}{l}\text { Semelhanças: interação com alunos no } \\
\text { processo de ensino e de aprendizagem }\end{array}$ & $\begin{array}{l}\text { Depende: da disposição e interesse do } \\
\text { professor }\end{array}$ \\
\hline $\begin{array}{l}\text { Semelhanças: tanto a metodologia de } \\
\text { trabalho presencial como a virtual } \\
\text { possibilitam o ensino e a aprendizagem }\end{array}$ & $\begin{array}{l}\text { Depende: da flexibilidade e dinamismo da } \\
\text { metodologia de ensino utilizada. }\end{array}$ \\
\hline Semelhanças: avaliação do processo & $\begin{array}{l}\text { Depende: não transpor simplesmente aulas } \\
\text { do presencial para o virtual }\end{array}$ \\
\hline \multicolumn{2}{|l|}{$\begin{array}{l}\text { Semelhanças: ambos devem estar } \\
\text { centrados na aprendizagem do aluno }\end{array}$} \\
\hline \multicolumn{2}{|l|}{ Semelhanças: objetivos e estratégias } \\
\hline \multicolumn{2}{|l|}{$\begin{array}{l}\text { Semelhanças: criação de situações de } \\
\text { aprendizagem }\end{array}$} \\
\hline \multicolumn{2}{|l|}{$\begin{array}{l}\text { Semelhanças: organização do plano } \\
\text { pedagógico e orientação sobre o } \\
\text { andamento da disciplina }\end{array}$} \\
\hline $\begin{array}{l}\text { Semelhanças: criatividade e trocas } \\
\text { professor-aluno }\end{array}$ & \\
\hline
\end{tabular}


$\mathrm{Na}$ análise realizada no segundo questionário (implementado ao final do terceiro momento pedagógico) pode-se perceber que as diferenças apontadas estão relacionadas à interação entre os participantes da aula, seja ela presencial ou não; utilização de um maior número de ferramentas e recursos, sem contar a diversidade de metodologias; maior dedicação e habilidade do professor virtual do que do presencial. Além disso, as semelhanças apontadas pelos alunos foram quanto a avaliação do processo de aprendizagem; aos objetivos e estratégias de ensino; organização do plano pedagógico e que em ambos o professor deve estar centrado na aprendizagem dos alunos.

Pode-se notar também que os sujeitos fazem distinção quando opinam sobre a possibilidade de o professor habituado com o ensino presencial estar em condições de desenvolver aulas no meio on-line. Para alguns, seria necessário que tal professor passasse por um novo processo de formação. Para outros, seria suficiente que ele participasse de cursos de capacitação. Isso indica que o tema é controverso e que necessita de maior reflexão.

A atividade final de apresentação dos planos de aula em EAD propiciou verificar, também, como os conceitos trabalhados, as atividades realizadas, as discussões e reflexões encontravam-se na prática docente construída pelos alunos. A elaboração de uma aula apenas virtual confrontou os sujeitos em como proceder sem o contato presencial.

Concluiu-se que o discurso oral e escrito, na maioria da turma, demonstrava conhecimentos e compreensão das semelhanças e mudanças educacionais oriundas da atividade docente virtual. No entanto, na atividade final proposta que se concentrava na elaboração de uma aula, um encontro à distância, quase metade da turma ao apresentar suas propostas, não conseguiu se desprender do encontro presencial, seguiram o modelo semi-presencial da oficina que estavam realizando. Percebeu-se, com isso, que a metodologia dos TMP foi facilmente assimilada pelos alunos participantes da oficina, porém também caracterizou de certa forma que os modelos utilizados na prática docente estão embasados em experiências cotidianas e ao deparar-se com novas propostas, inicialmente recorre-se a estes modelos, mesmo que se compreendam as mudanças. mudanças.

inicialmente recorre-se a estes modelos, mesmo que se compreendam as

\section{Considerações finais}

Ao final da oficina, as expressões mencionadas, nos questionários, continuaram compondo a concepção de grande parte da turma, no entanto novas concepções surgiram as quais vão além de apenas palavras e sim apresentam conceitos, que envolvem o papel do professor como incentivador da construção de trabalhos colaborativos e proporcionando aos alunos maior autonomia e autoria.

Os resultados obtidos com a adoção dessa metodologia mostraram que podem servir como inspiração para outros professores, de várias disciplinas, para desenvolver as suas próprias atividades e aplicá-las em suas turmas obtendo sucesso no processo de ensino e de aprendizagem, seja ele presencial ou virtual. 
A conjugação das diferentes atividades didáticas, a integração entre a teoria e a prática, com o desenvolvimento de conceitos, procedimentos e atitudes de modo coletivo e progressivo pode produzir resultados positivos para o ensino e a aprendizagem. Os avanços decorrentes de seu maior envolvimento pessoal com as atividades fazem com que os alunos tornem-se mais confiantes e mais recompensados, $o$ que se constituiu em um fator motivador e incentivador de novas aprendizagens.

Apesar da complexidade inicial de se trabalhar com esta metodologia, ela se constitui em um recurso valioso, capaz de promover uma maior participação dos alunos em aula e colaborar para a motivação dos alunos, tornando o ensino estimulante e colaborando para a aprendizagem dos conteúdos estudados.

\section{Agradecimentos}

Esse trabalho foi parcialmente financiado por FAPEAM e CNPq.

\section{Referências}

Behar, Patricia Alejandra et al. Modelos Pedagógicos em Educação a Distância. Porto Alegre: Artmed, p.17, 2009.

Collins, M.; Berge, Z.L. Facilitating interaction in computer mediated online courses. FSU/AECT Distance Education Conference, Tallahasee FL, http://star.ucc.nau.edu/ mauri/moderate/flcc.html, June, 1996.

Delizoicov, D.; Angotti, J. Física. 2a ed. São Paulo: Cortez, 1991.

Delizoicov, D.; Angotti, J.; Pernambuco, M.M. Ensino de Ciências: fundamentos e métodos. São Paulo: Cortez, 2002.

Sherry, L. The nature and purpose of online discourse: a brief synthesis of current research as related to the WEB project. International Journal of Educational Telecommunications, 1998.

Zavaski, Ediana. Do real ao virtual: novas possibilidades das práticas pedagógicas nos laboratórios de informática. Dissertação (mestrado) - Universidade Federal do Rio Grande do Sul, Pós-Graduação em Educação, Porto Alegre, 2005. 